\title{
Intelectin 1 suppresses tumor progression and is associated with improved survival in gastric cancer
}

\author{
Dan Li ${ }^{1, *}$, Xiang Zhao ${ }^{1, *}$, Yong Xiao ${ }^{1, *}$, Hong Mei $^{1}$, Jiarui Pu ${ }^{1}$, Xuan Xiang ${ }^{1}$, Wanju Jiao ${ }^{2}$, \\ Huajie Song $^{1}$, Hongxia Qu ${ }^{1}$, Kai Huang ${ }^{3,4}$, Liduan Zheng ${ }^{2,3}$, Qiangsong Tong ${ }^{1,3}$ \\ ${ }^{1}$ Department of Surgery, Union Hospital, Tongji Medical College, Huazhong University of Science and Technology, Wuhan, \\ P. R. China \\ ${ }^{2}$ Department of Pathology, Union Hospital, Tongji Medical College, Huazhong University of Science and Technology, Wuhan, \\ P. R. China \\ ${ }^{3}$ Clinical Center of Human Genomic Research, Union Hospital, Tongji Medical College, Huazhong University of Science and \\ Technology, Wuhan, P. R. China \\ ${ }^{4}$ Department of Cardiology, Union Hospital, Tongji Medical College, Huazhong University of Science and Technology, Wuhan, \\ P. R. China \\ "These authors have contributed equally to this work
}

Correspondence to:

Qiangsong Tong, e-mail: qs_tong@hotmail.com

Liduan Zheng, e-mail: Id_zheng@hotmail.com

Keywords: gastric cancer, intelectin 1, hepatocyte nuclear factor 4 alpha, nuclear factor-kappa B

Received: October 02, 2014

Accepted: April 06, 2015

Published: April 20, 2015

\section{ABSTRACT}

Recent evidence shows the emerging roles of intelectin 1 (ITLN1), a secretory lectin, in human cancers. Our previous studies have implicated the potential roles of ITLN1 in the aggressiveness of gastric cancer. Herein, we investigated the functions, downstream targets, and clinical significance of ITLN1 in the progression of gastric cancer. We demonstrated that ITLN1 increased the levels of hepatocyte nuclear factor 4 alpha (HNF4a), resulting in suppression of nuclear translocation and transcriptional activity of $\beta$-catenin in gastric cancer cells. Mechanistically, ITLN1 attenuated the activity of nuclear factor-kappa B, a transcription factor repressing the HNF4a expression, in gastric cancer cells through inactivating the phosphoinositide 3-kinase/ AKT/Ikappa B kinase signaling. Gain- and loss-of-function studies demonstrated that ITLN1 suppressed the growth, invasion, and metastasis of gastric cancer cells in vitro and in vivo. In addition, restoration of HNF4a expression prevented the gastric cancer cells from ITLN1-mediated changes in these biological features. In clinical gastric cancer tissues, HNF4a expression was positively correlated with that of ITLN1. Patients with high ITLN1 or HNF4a expression had greater survival probability. Taken together, these data indicate that ITLN1 suppresses the progression of gastric cancer through up-regulation of HNF4a, and is associated with improved survival in patients with gastric cancer.

\section{INTRODUCTION}

Gastric cancer is one of the most common cancers worldwide, with approximately 1 million new cases being diagnosed annually [1]. In Asia and parts of South America, gastric cancer is the leading cause of cancerrelated death, with a 5-year survival rate below $30 \%$ [1]. Better elucidating the mechanisms of tumorigenesis and aggressiveness is important for improving the therapeutic efficiency of gastric cancer [2]. Recent studies have shown that galectins, a family of mammalian lectins that bind $\beta$-galactoside, are frequently over-expressed in many human solid and blood malignancies, and exert important functions in tumor biology, including the transformation, growth, adhesion, invasion, and metastasis of cancer cells [3]. Inhibition of galectin-1 expression using an 
antisense RNA abolishes the membrane anchorage of oncogenic Harvey rat sarcoma viral oncogene homolog (HRAS), and inhibits the HRAS-induced transformation [4]. Galectin-1 also promotes the adhesion of ovarian and prostate cancer cells to extracellular matrix $[5,6]$, while galectin-3 significantly suppresses the growth and metastasis of breast cancer cells [7]. Galectin- 8 reduces the migration of colon cancer cells, indicating its suppressive roles in tumor aggressiveness [8]. Therefore, it is necessary to investigate the roles of lectins in the progression of gastric cancer.

Intelectin 1 (ITLN1), a recently identified secretory and galactofuranose-binding lectin, is mainly expressed in the gastrointestinal goblet cells and omentum, and occasionally in the thymus, bronchus, heart, liver, kidney collecting tubule cells, bladder umbrella and mesothelial cells $[9,10]$. Subsequent studies have demonstrated that ITLN1 is involved in the gut immune defense against microorganisms [9, 11-13], insulin-stimulated glucose uptake [14], chronic obstructive pulmonary disease [15], and asthma [16]. Importantly, recent evidence shows that ITLN1 is over-expressed in human malignant pleural mesothelioma (MPM) and secreted into pleural effusions, and serves as a biomarker for distinguishing MPM from lung cancer $[17,18]$, implicating the emerging roles of ITLN1 in human cancers.

Our previous studies have shown that ITLN1 is aberrantly expressed in gastric cancer, and is a potential prognostic factor for predicting the outcome of gastric cancer patients [19]. However, the exact functions, downstream targets, and clinical significance of ITLN1 in gastric cancer still remain elusive. In the current study, we demonstrate, for the first time, that secretory ITLN1 suppresses the growth, invasion, and metastasis of gastric cancer cells in vitro and in vivo through up-regulating hepatocyte nuclear factor 4 alpha $(\mathrm{HNF} 4 \alpha)$, and is associated with improved survival of gastric cancer patients. In addition, the activity of nuclear factor-kappa $\mathrm{B}(\mathrm{NF} \kappa \mathrm{B})$, a transcription factor repressing the expression of $\mathrm{HNF} 4 \alpha$, is attenuated by ITLN1 via inactivation of phosphoinositide 3-kinase (PI3K)/AKT/Ikappa B kinase (IKK) signaling, suggesting the tumor suppressive roles of ITLN1 in gastric cancer.

\section{RESULTS}

\section{ITLN1 facilitated the expression of HNF4 $\alpha$ at transcriptional levels in gastric cancer cells}

To investigate the potential roles of ITLN1 in gastric cancer, ITLN1 vector was constructed and stably transfected into cultured gastric cancer cell lines, SGC-7901 and AGS, resulting in enhanced ITLN1 secretion into culture supernatant (Figure 1A). Microarray and gene ontology analyses revealed that stable transfection of ITLN1 into SGC-7901 cells resulted in altered transcript levels of 1592 human genes, including 547 up-regulated and 1045 down-regulated ones, and regulation of cellular process was the top-ranked function of ITLN1 in gastric cancer cells (Figure S1). Notably, among 331 ITLN1-altered (91 up-regulated and 240 down-regulated) genes involved in the cellular process (Table S1), HNF4 $\alpha$ was identified as the most up-regulated one (Figure 1B). Real-time quantitative RT-PCR and western blot further demonstrated that stable transfection of ITLN1 increased the transcript and protein levels of $\mathrm{HNF} 4 \alpha$, when compared to those stably transfected with empty vector (mock) (Figure 1C and Figure 1D). In addition, administration of recombinant ITLN1 protein ( 1 and $2 \mu \mathrm{g} / \mathrm{ml}$ ) into cultured gastric cancer cell lines also markedly induced the HNF4 $\alpha$ expression at 24 and $36 \mathrm{hrs}$ post-administration (Figure 1E). Moreover, the nuclear translocation of $\beta$-catenin, a target gene of HNF4 $\alpha$ [20] (Figure S2A and Figure S2B), was correspondingly decreased in SGC-7901 and AGS cells stably transfected with ITLN1 than mock cells (Figure 1C, Figure 1D, and Figure S2C). To further examine the effects of ITLN1 on HNF4 $\alpha$ expression, we performed the ITLN1 knockdown experiments. Stable transfection of short hairpin RNA (shRNA) specific for ITLN1 (sh-ITLN1) led to reduced ITLN1 secretion (Figure 1F, Figure 1G, and Figure S3A), decreased HNF4 $\alpha$ expression (Figure 1F, Figure 1G, and Figure $\mathrm{S} 3 \mathrm{~B}$ ), and increased nuclear translocation of $\beta$-catenin (Figure 1F and Figure S2D). Moreover, stable over-expression or knockdown of ITLN1 in gastric cancer cells decreased and increased the $\beta$-catenin activity and transcription of downstream genes axin 2 (AXIN2) [21], cyclin D2 (CCND2) [22], runt-related transcription factor 2 (RUNX2) [23], and matrix metallopeptidase 3 (MMP3) [24], respectively, which was abolished by knockdown or ectopic expression of HNF4 $\alpha$ (Figure 1H, Figure S2E, Figure S2F, and Figure S3B). Overall, these results demonstrated that ITLN1 considerably facilitated the HNF4 $\alpha$ expression at transcriptional levels in gastric cancer cells.

\section{Crucial roles of NFKB in ITLN1-mediated regulation of $\mathrm{HNF} 4 \alpha$ in gastric cancer cells}

To investigate the mechanisms underlying ITLN1-mediated up-regulation of $\mathrm{HNF} 4 \alpha$, we analyzed the transcription factor binding sites within the $H N F 4 \alpha$ promoter, and noted one potential binding site of $\mathrm{NF} \kappa \mathrm{B}$, locating at bases 508-522 upstream the transcription start site (TSS) (Figure 2A). Chromatin immunoprecipitation (ChIP) and quantitative PCR (qPCR) assays indicated that the endogenous NFאB-targeting $H N F 4 \alpha$ promoter regions were immunoprecipitated using antibody specific for

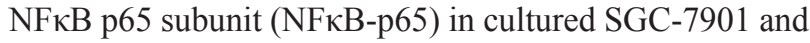
AGS cells, which were 0.44 - and 0.36 -fold by normalizing to nuclear extract (input; Figure 2A). As controls, no $H N F 4 \alpha$ promoter regions were immunoprecipitated with 
A

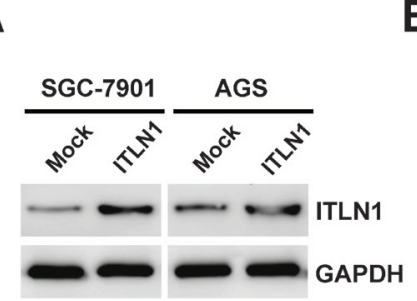

D

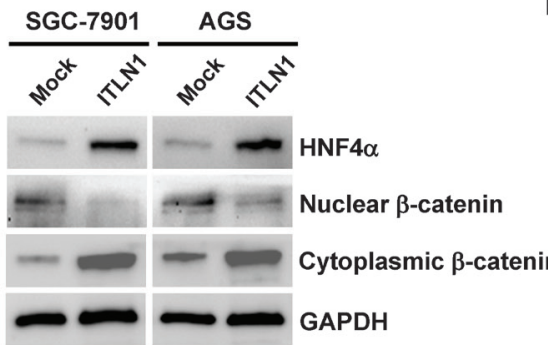

B

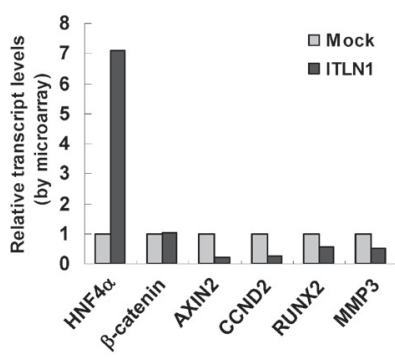

C

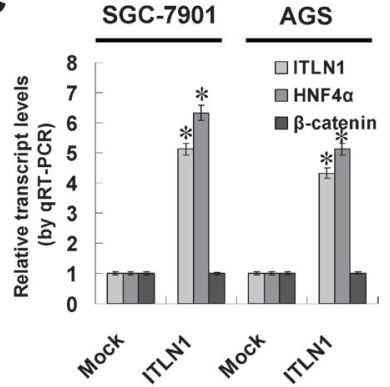

E

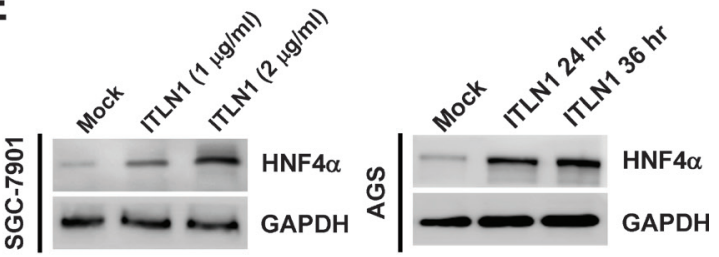

F
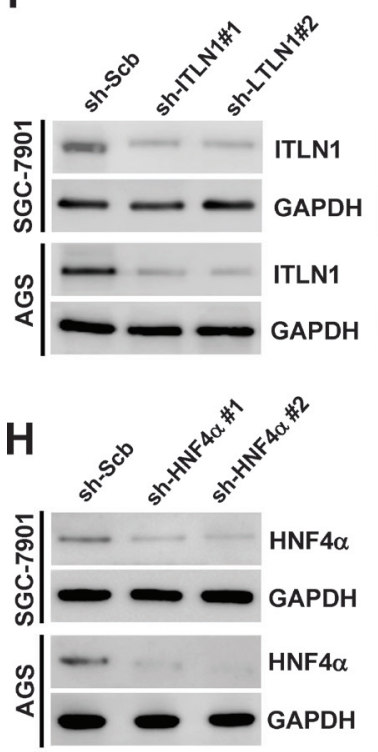

SGC-7901 AGS
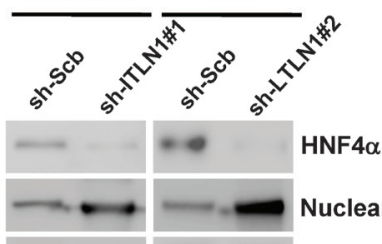

Nuclear $\beta$-catenin

Cytoplasmic $\beta$-catenin

GAPDH

G
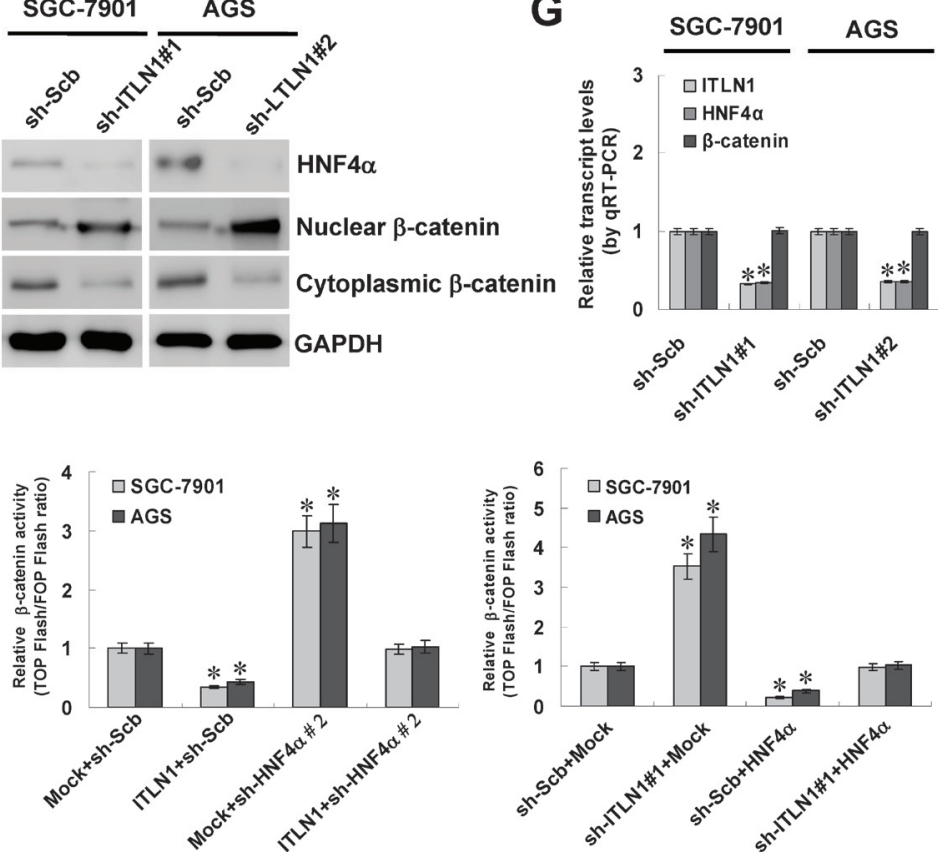

Figure 1: ITLN1 facilitated the expression of HNF4 $\alpha$ in gastric cancer cells. A. ITLN1 expression vector was stably transfected into cultured gastric cancer cell lines, SGC-7901 and AGS, resulting in increased secretion of ITLN1 into culture supernatant. B. microarray analysis revealed the up-regulation of HNF4 $\alpha$ in SGC-7901 cells stably transfected with ITLN1. C and D. real-time quantitative RTPCR and western blot further demonstrated that stable transfection of ITLN1 into SGC-7901 and AGS cells increased the transcript and protein levels of $\mathrm{HNF} 4 \alpha$, when compared to those stably transfected with empty vector (mock). In addition, the nuclear translocation of $\beta$-catenin was also decreased in ITLN1 over-expressing SGC-7901 and AGS cells than those in mock cells ( ${ }^{*} P<0.01$ vs. mock). E. recombinant ITLN1 protein $(1$ and $2 \mu \mathrm{g} / \mathrm{ml})$ induced the HNF4 $\alpha$ expression in SGC-7901 cells at 24 hrs post-administration, than those treated with solvent control (mock). Administration of ITLN1 protein $(1 \mu \mathrm{g} / \mathrm{ml})$ into AGS cells for 24 and 36 hrs resulted in enhanced HNF4 $\alpha$ expression than that of mock cells. F and G. western blot and real-time quantitative RT-PCR indicated that stable transfection of ITLN1 shRNA obviously reduced the ITLN1 secretion and down-regulated the HNF4 $\alpha$ expression of SGC-7901 and AGS cells, than those of scramble shRNA (sh-Scb)-transfected cells. Moreover, the nuclear translocation of $\beta$-catenin was also increased in SGC-7901 and AGS cells transfected with ITLN1 shRNA, when compared with those transfected with sh-Scb ( ${ }^{*}<0.01 \mathrm{vs.} \mathrm{sh-Scb).} \mathrm{H.} \mathrm{western} \mathrm{blot} \mathrm{and} \mathrm{dual-}$ luciferase assays indicated that transfection of shRNA specific for HNF4 $\alpha$ resulted in its down-regulation in SGC-7901 and AGS cells. Stable over-expression or knockdown of ITLN1 decreased and increased the $\beta$-catenin activity in gastric cancer cells, respectively, which was abolished by knockdown or over-expression of $\mathrm{HNF} 4 \alpha(* P<0.01$ vs. mock or sh-Scb). 
unspecific antibody (isotype $\mathrm{IgG}$ ) or detected by qPCR with primer set $(-339 /-158 \mathrm{bp})$ distal to the binding site of NF $\kappa \mathrm{B}$ (Figure 2A). In addition, over-expression or knockdown of ITLN1 in SGC-7901 and AGS cells decreased and increased the binding of NFкB-p65 on $-606 /-409$ bp region of the $H N F 4 \alpha$ promoter, which was rescued by over-expression and knockdown of NFкB-p65, respectively (Figure 2B). In addition, dualluciferase assay indicated that ITLN1 facilitated the $H N F 4 \alpha$ promoter activity, and ectopic expression or knockdown of NFKB-p65 restored the changes in $H N F 4 \alpha$ promoter activity induced by stable transfection of ITLN1 or sh-ITLN1 in gastric cancer cells, while these effects were abolished by mutation of NFkB-p65 binding site (Figure 2C). Importantly, western blot and real-time quantitative RT-PCR indicated that ectopic expression or knockdown of NFkB-p65 decreased and increased the expression of $\mathrm{HNF} 4 \alpha$, respectively, and prevented the gastric cancer cells from ITLN1-mediated changes in HNF $4 \alpha$ expression (Figure 2D, Figure 2E, Figure S3C, Figure S3D, and Figure S3E). These results indicated that $\mathrm{NF} \kappa \mathrm{B}$ repressed the transcription of $H N F 4 \alpha$, and ITLN1 attenuated the function of NFKB to up-regulate HNF4 $\alpha$ in gastric cancer cells.

\section{ITLN1 attenuated the NFKB activity in gastric cancer cells via inactivation of PI3K/AKT/IKK signaling}

To further explore the roles of NFKB in ITLN1mediated regulation of $\mathrm{HNF} 4 \alpha$, we observed the changes in PI3K/AKT/IKK signaling that regulates the activity of $\mathrm{NF} \kappa \mathrm{B}[25]$. Administration of recombinant ITLN1 protein (1 $\mu \mathrm{g} / \mathrm{ml}$ ) into SGC-7901 cells resulted in decreased phosphorylation of AKT (T308 and S473), IKK $\alpha / \beta$ (S180/

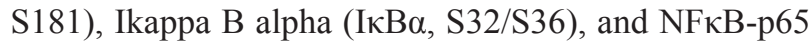
(S536) at 24 and $36 \mathrm{hrs}$, than those treated with solvent control (mock) (Figure 3A). In contrast, stable knockdown of ITLN1 induced the phosphorylation of AKT (T308 and S473), IKK $\alpha / \beta$ (S180/S181), IкB $\alpha(\mathrm{S} 32 / \mathrm{S} 36)$, and NFkB-p65 (S536) in gastric cancer cells, which were abolished by administration of PI3K activity inhibitor LY294002 and IKK inhibitor BAY11-7082 (Figure 3B). Accordingly, stable over-expression or knockdown of ITLN1 decreased and increased the $\mathrm{NF \kappa B}$ activity in SGC-7901 and AGS cells, respectively (Figure 3C). These data indicated that ITLN1 inhibited the NFKB activity through attenuating the $\mathrm{PI} 3 \mathrm{~K} / \mathrm{AKT} / \mathrm{IKK}$ signaling in gastric cancer cells.

\section{Ectopic expression of ITLN1 suppressed the growth, migration, and invasion of gastric cancer cells through up-regulating HNF4a}

Since previous studies indicate that HNF $4 \alpha$ affects the growth, invasion, and metastasis of cancers [26, 27], and combining the evidence that ITLN1 regulated the HNF4 $\alpha$ expression, we further investigated the effects of ITLN1 over-expression and target gene restoration on cultured gastric cancer cells. Western blot and real-time quantitative RT-PCR indicated that transfection of shRNA targeting $H N F 4 \alpha$ resulted in its down-regulation, and restored the ITLN1-induced up-regulation of $\mathrm{HNF} 4 \alpha$ in SGC-7901 and AGS cells (Figure 4A and Figure S3F). In colony formation assay, ITLN1 over-expression attenuated the growth of SGC-7901 and AGS cells, when compared to those stably transfected with empty vector (mock) (Figure 4B and Figure S4A). In scratch assay, ITLN1 over-expression attenuated the migration capability of SGC-7901 and AGS cells (Figure 4C and Figure S4B). Matrigel invasion assay showed that gastric cancer cells stably transfected with ITLN1 presented an impaired invasion capacity than mock cells (Figure 4D). In addition, restoration of HNF4 $\alpha$ expression via shRNA transfection rescued the SGC-7901 and AGS cells from their changes in growth, migration, and invasion induced by stable overexpression of ITLN1 (Figure 4B, Figure 4C, Figure 4D, Figure S4A, and Figure S4B). These results revealed the tumor suppressive roles of ITLN1, and indicated that up-regulation of HNF4 $\alpha$ was involved in ectopic ITLN1 expression-inhibited aggressiveness of gastric cancer cells.

\section{Knockdown of ITLN1 promoted the growth, migration, and invasion of gastric cancer cells in vitro}

To further explore the impacts of ITLN1 on the aggressiveness of gastric cancer cells, we investigated the effects of ITLN1 knockdown and HNF4 $\alpha$ restoration on cultured gastric cancer cells. Western blot and realtime quantitative RT-PCR indicated that transfection of $H N F 4 \alpha$ resulted in its over-expression and restored the down-regulation of $\mathrm{HNF} 4 \alpha$ induced by ITLN1 knockdown in SGC-7901 and AGS cells (Figure 4E and Figure S3G). In colony formation assay, knockdown of ITLN1 facilitated the growth of SGC-7901 and AGS cells, when compared to those stably transfected with scramble shRNA (sh-Scb) (Figure 4F and Figure S4C). In scratch assay, ITLN1 knockdown increased the migration capability of SGC-7901 and AGS cells (Figure 4G and Figure S4D). Matrigel invasion assay showed that gastric cancer cells stably transfected with sh-ITLN1 presented an increased invasion capacity than sh-Scb-transfected cells (Figure 4H). In addition, restoration of $H N F 4 \alpha$ expression via transfection of $H N F 4 \alpha$ vector rescued the SGC-7901 and AGS cells from their changes in growth, migration, and invasion induced by stable knockdown of ITLN1 (Figure 4F, Figure 4G, Figure 4H, Figure S4C, and Figure S4D). These findings suggested that identification of $H N F 4 \alpha$ as an ITLN1 target gene may explain, at least in part, why ITLN1 suppressed the growth, migration, and invasion of gastric cancer cells. 


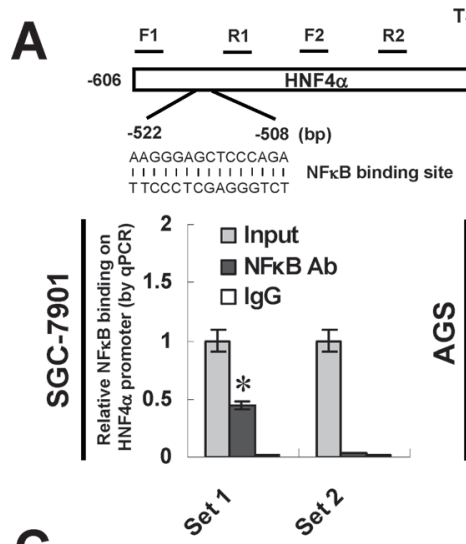

$\stackrel{\text { TSS }}{\longrightarrow}$
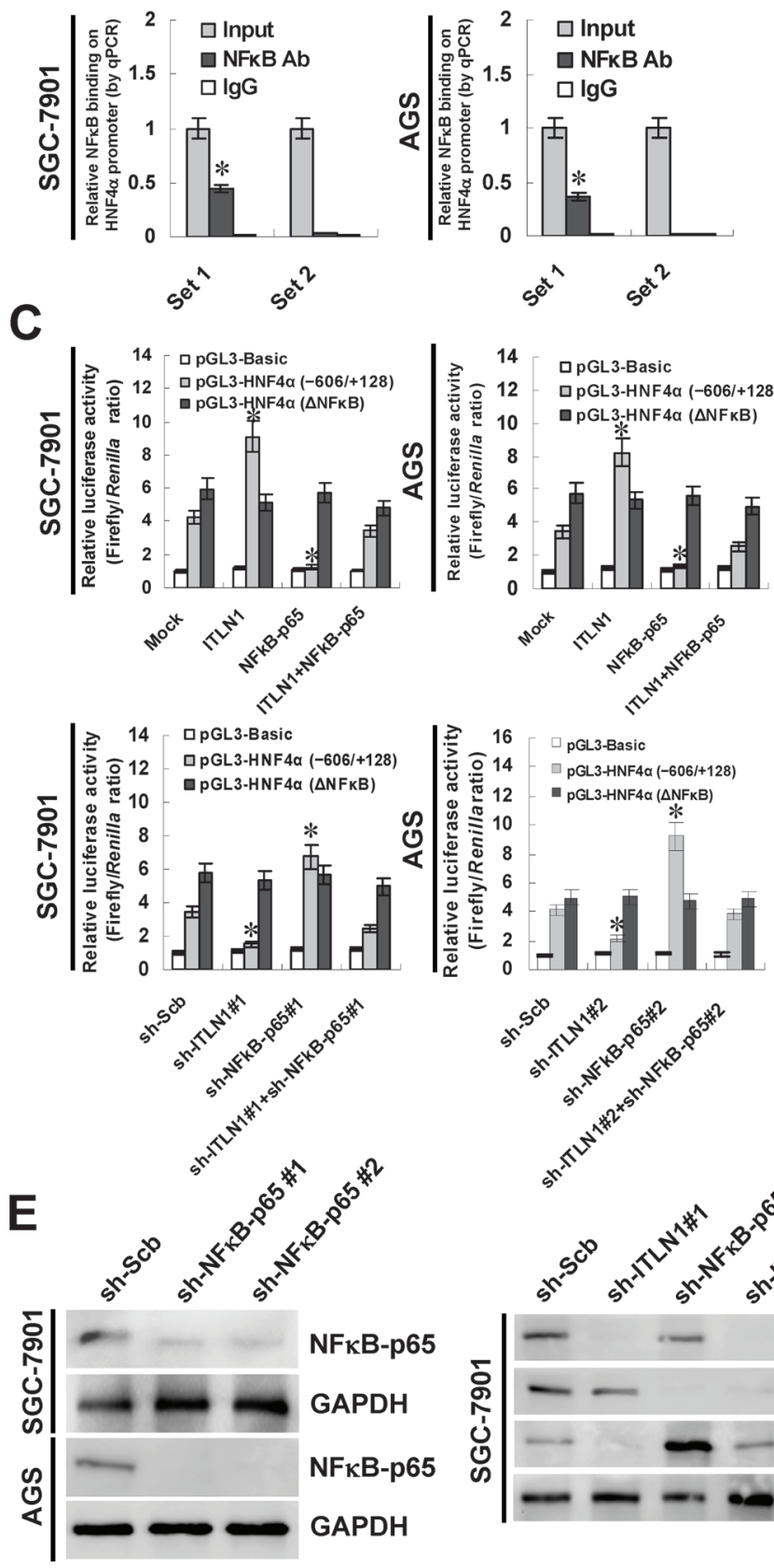

pGL3-HNF4a ( $\triangle N F$ KB)
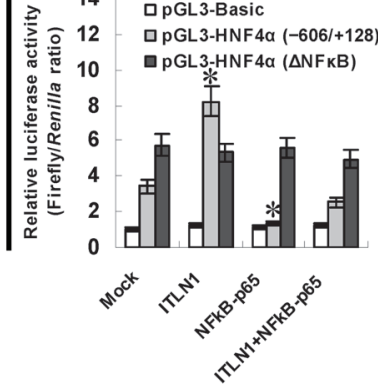

B

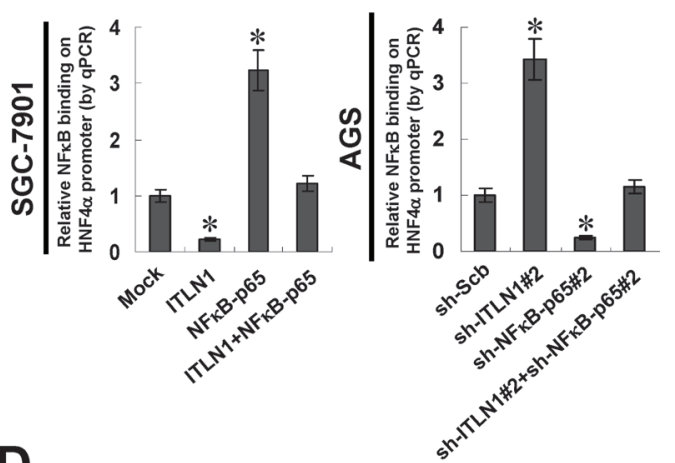

D

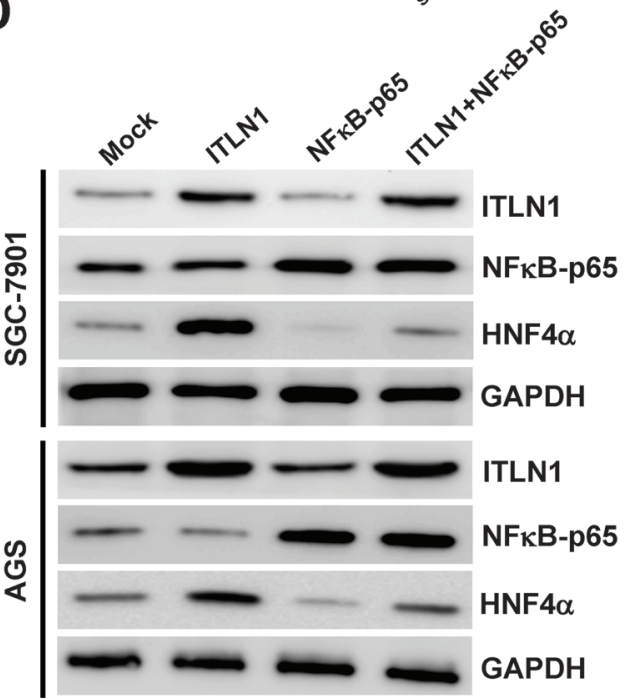

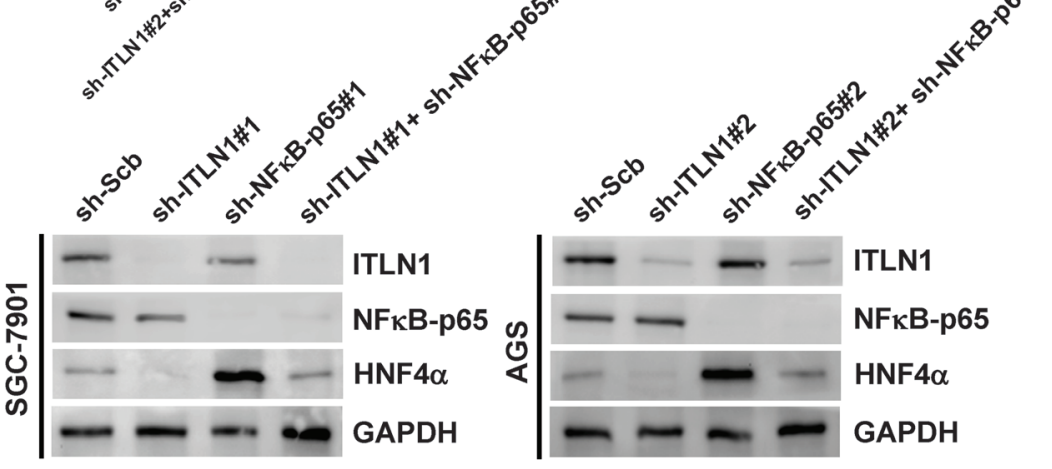

Figure 2: Crucial roles of NFKB in ITLN1-mediated regulation of HNF4 $\alpha$ expression in gastric cancer cells. A. one potential binding site of NFKB was noted within the HNF4a promoter, locating at bases 508-522 upstream the transcription start site (TSS). ChIP and qPCR assays indicated the endogenous binding of NFkB-p65 on -606/-409 bp region, but not on -339/-158 region, of the HNF4 $\alpha$ promoter in SGC-7901 and AGS cells. B. ChIP and qPCR assays indicated that over-expression or knockdown of ITLN1 decreased and increased the binding of NFKB-p65 on the $H N F 4 \alpha$ promoter, which was rescued by over-expression and knockdown of NFKB-p65 ( $* P<0.01$ vs. mock or sh-Scb). C. dual-luciferase assay indicated that stable transfection of ITLN1 or sh-ITLN1 into gastric cancer cells facilitated or suppressed the promoter activity of $H N F 4 \alpha$ than those in mock or sh-Scb-transfected cells, respectively, which was rescued by transfection of $N F \kappa B-p 65$ or sh-NFkB-p65. In addition, mutation of NFKB binding site abolished these effects $(* P<0.01$ vs. sh-Scb or mock). D. western blot assay indicated that transfection of $N F \kappa B-p 65$ prevented the gastric cancer cells from ITLN1-mediated up-regulation of HNF4 $\alpha$. E. western blot assay indicated that knockdown of NFKB-p65 prevented gastric cancer cells from sh-ITLN1repressed expression of HNF $4 \alpha$. 
A

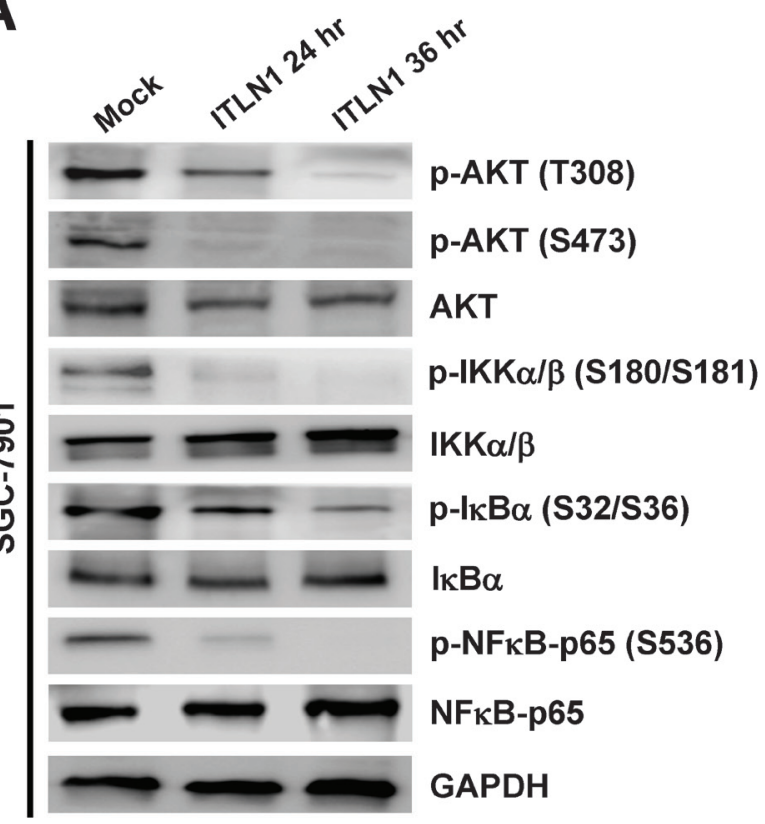

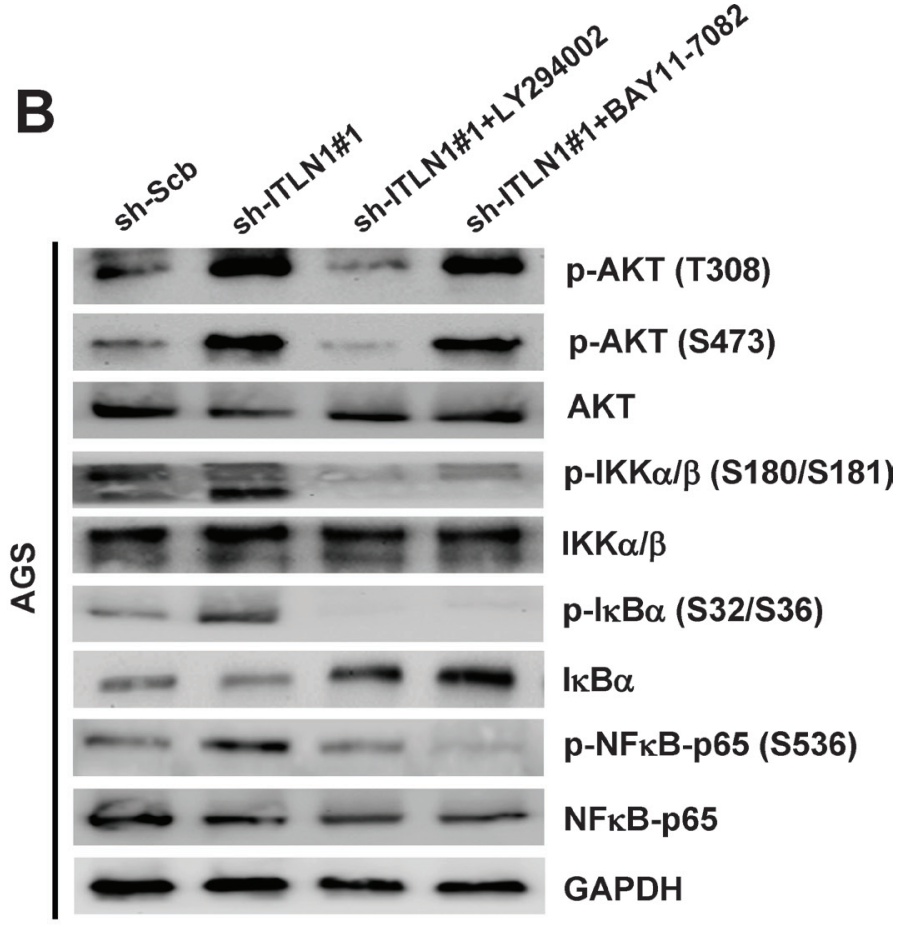

C

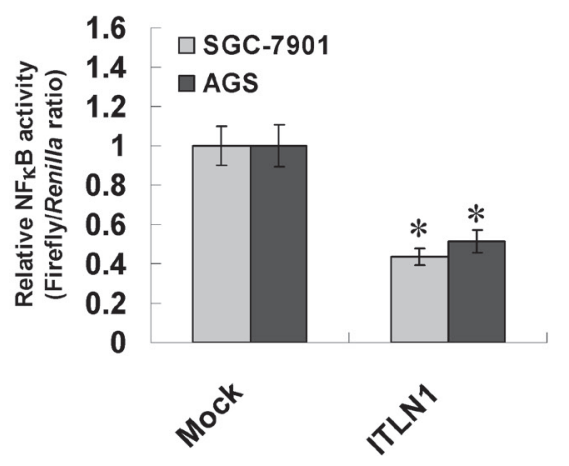

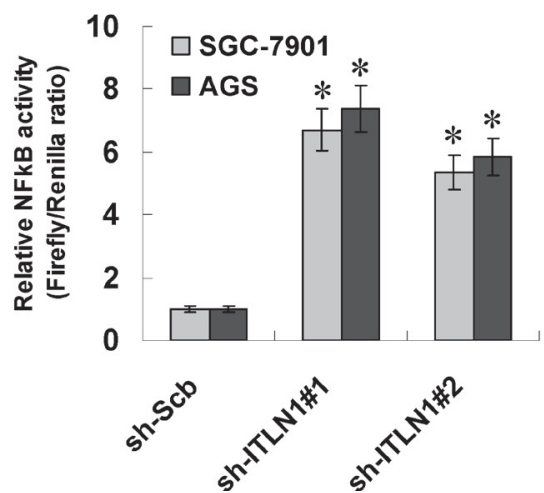

Figure 3: ITLN1 attenuated the NFKB activity via inactivation of PI3K/AKT/IKK signaling in gastric cancer cells. A. western blot assay indicated that administration of recombinant ITLN1 protein $(1 \mu \mathrm{g} / \mathrm{ml}$ for 24 and $36 \mathrm{hrs})$ reduced the phosphorylation of AKT (T308 and S473), IKK $\alpha / \beta$ (S180/S181), IкB $\alpha$ (S32/S36), and NFkB-p65 (S536) in SGC-7901 cells, than those treated with solvent control (mock). B. western blot assay indicated that stable transfection of ITLN1 shRNA induced the phosphorylation of AKT (T308 and S473), IKK $\alpha / \beta$ (S180/S181), IкB $\alpha$ (S32/S36), and NFkB-p65 (S536) in gastric cancer AGS cells, than those of sh-Scbtransfected cells, which were abolished by administration of PI3K activity inhibitor LY294002 (10 $\mu \mathrm{mol} / \mathrm{L})$ and IKK inhibitor BAY 11-7082 $(50 \mathrm{mmol} / \mathrm{L})$. C. dual-luciferase assay indicated that ectopic expression or knockdown of ITLN1 decreased and increased the NFKB activity in SGC-7901 and AGS cells, than those transfected with mock or sh-Scb $(* P<0.01$ vs. mock or sh-Scb).

\section{ITLN1 suppressed the growth and metastasis of gastric cancer cells in vivo}

We next investigated the efficacy of ITLN1 against tumor growth and metastasis in vivo. Stable transfection of ITLN1 into SGC-7901 cells resulted in decreased growth and tumor weight of subcutaneous xenograft tumors in athymic nude mice, when compared to those stably transfected with empty vector (mock) (Figure 5A and Figure 5B). In the experimental metastasis studies, SGC-7901 cells stably transfected with ITLN1 established statistically fewer lung metastatic colonies than mock group (Figure 5C). On the other hand, stable knockdown of ITLN1 in SGC-7901 cells resulted in increased growth and tumor weight of subcutaneous xenograft tumors in athymic nude mice (Figure 5D and Figure 5E), and more lung metastatic colonies (Figure 5F), when compared to those stably transfected with sh-Scb. These results were 


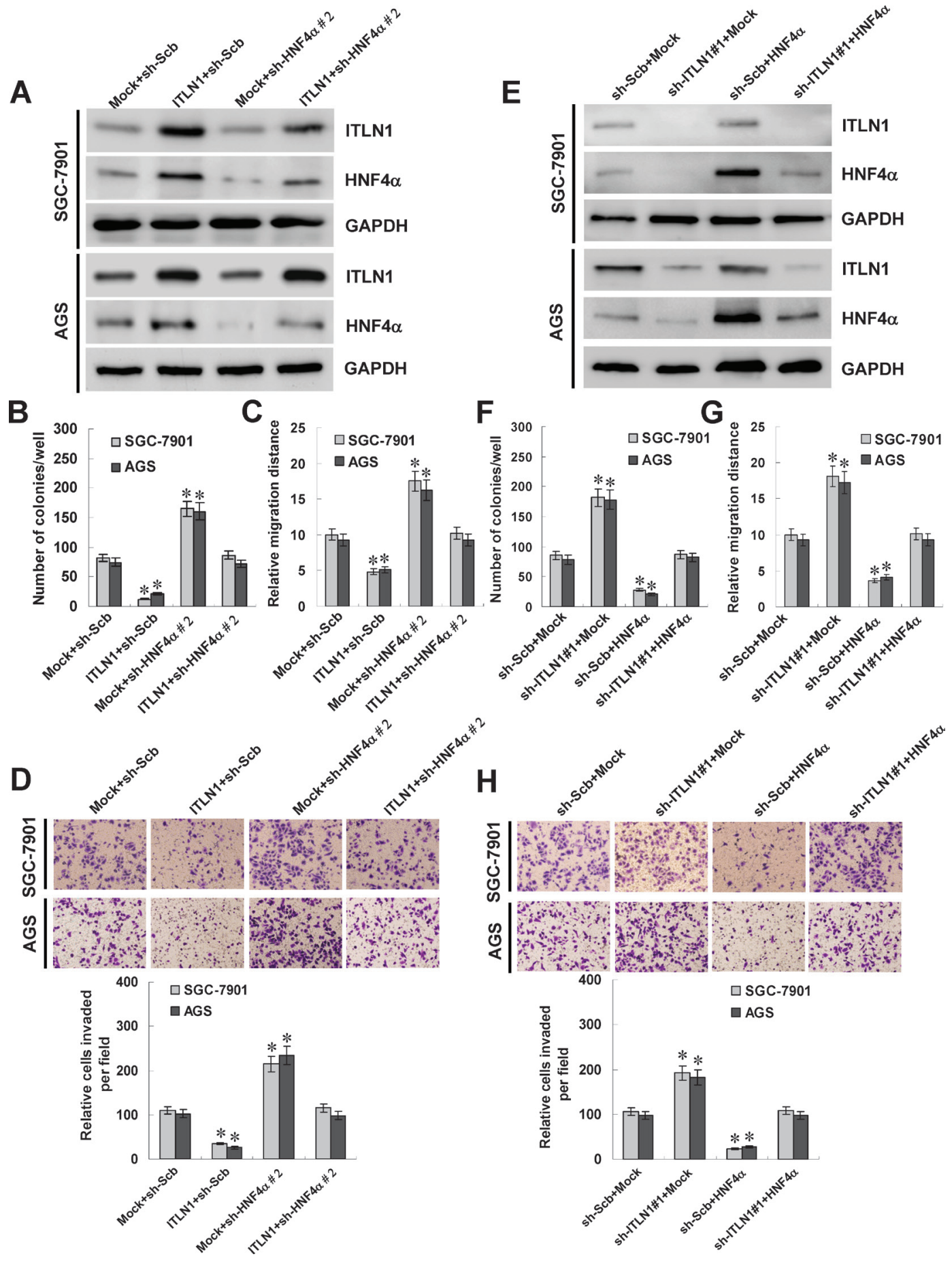

Figure 4: ITLN1 suppressed the growth, migration, and invasion of gastric cancer cells in vitro through up-regulating HNF4a. A and E. western blot indicated that stable transfection of ITLN1 or sh-ITLN1 into SGC-7901 and AGS cells enhanced and decreased the ITLN1 secretion, respectively, than those transfected with empty vector (mock) or sh-Scb. Transfection of sh-HNF4 $\alpha$ or $H N F 4 \alpha$ rescued the ITLN1-mediated changes in HNF4 $\alpha$ expression. B and F. colony formation assay indicated the decreased or enhanced cell viability of ITLN1 over-expressing or knocking down SGC-7901 and AGS cells. Transfection of sh-HNF4 $\alpha$ or $H N F 4 \alpha$ restored the colony formation of ITLN1 over-expressing and knocking down gastric cancer cells, respectively ( ${ }^{P} P<0.01 \mathrm{vs}$. mock or sh-Scb). C and G. in scratch assay, the migration of ITLN1 over-expressing or knocking down gastric cancer cells was significantly reduced or increased. Transfection of sh-HNF4 $\alpha$ or $H N F 4 \alpha$ rescued the migration of ITLN1 over-expressing and knocking down gastric cancer cells, respectively $\left({ }^{*} P<0.01\right.$ vs. mock or sh-Scb). D and $\mathbf{H}$. matrigel invasion assay indicated the decreased and increased invasion capability of ITLN1 over-expressing or knocking down gastric cancer cells. However, transfection of sh-HNF4 $\alpha$ or HNF4 $\alpha$ restored the invasion of ITLN1 over-expressing and knocking down gastric cancer cells, respectively $(* P<0.01$ vs. mock or sh-Scb). 

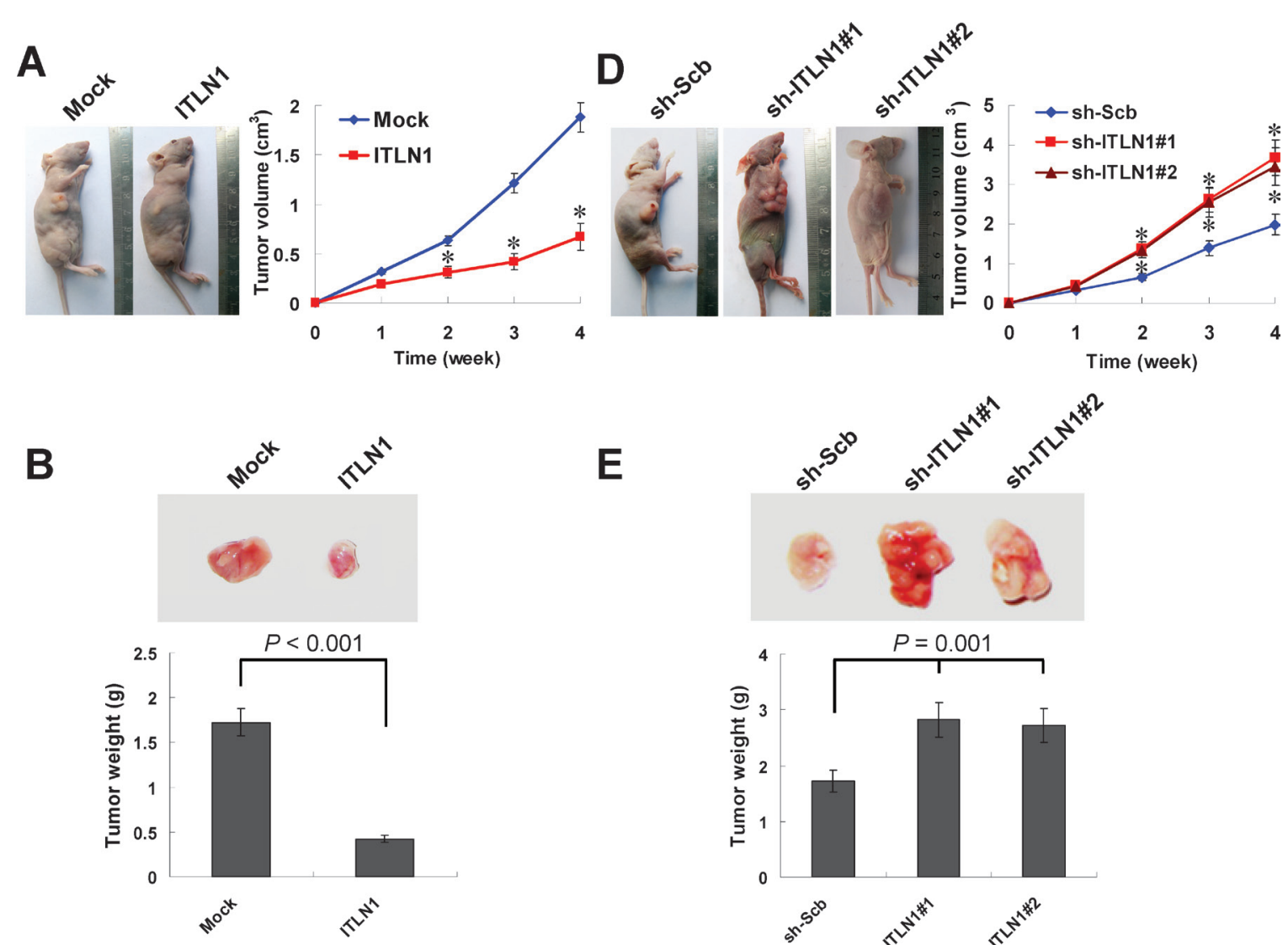

E
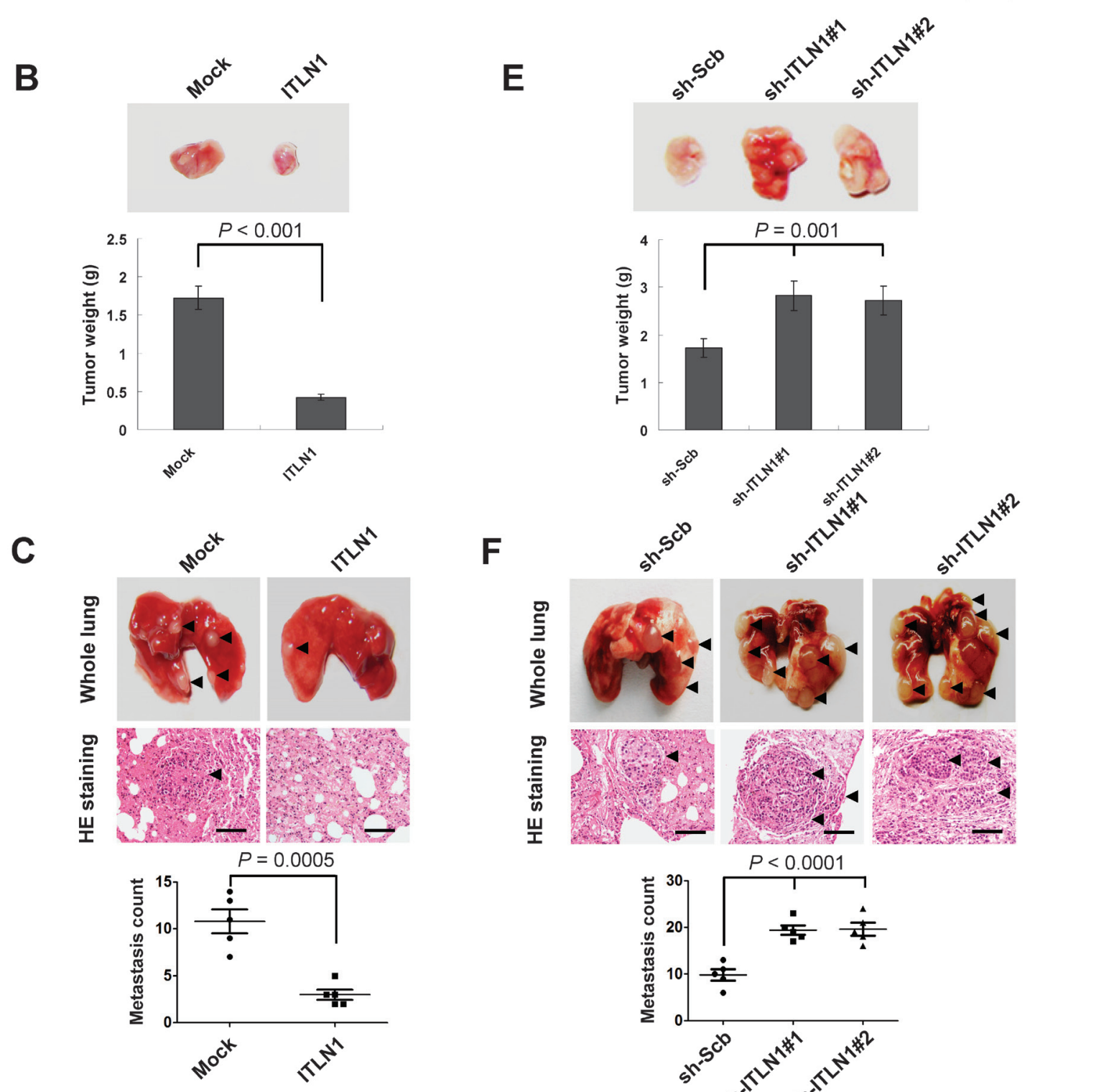

$\mathbf{F}$
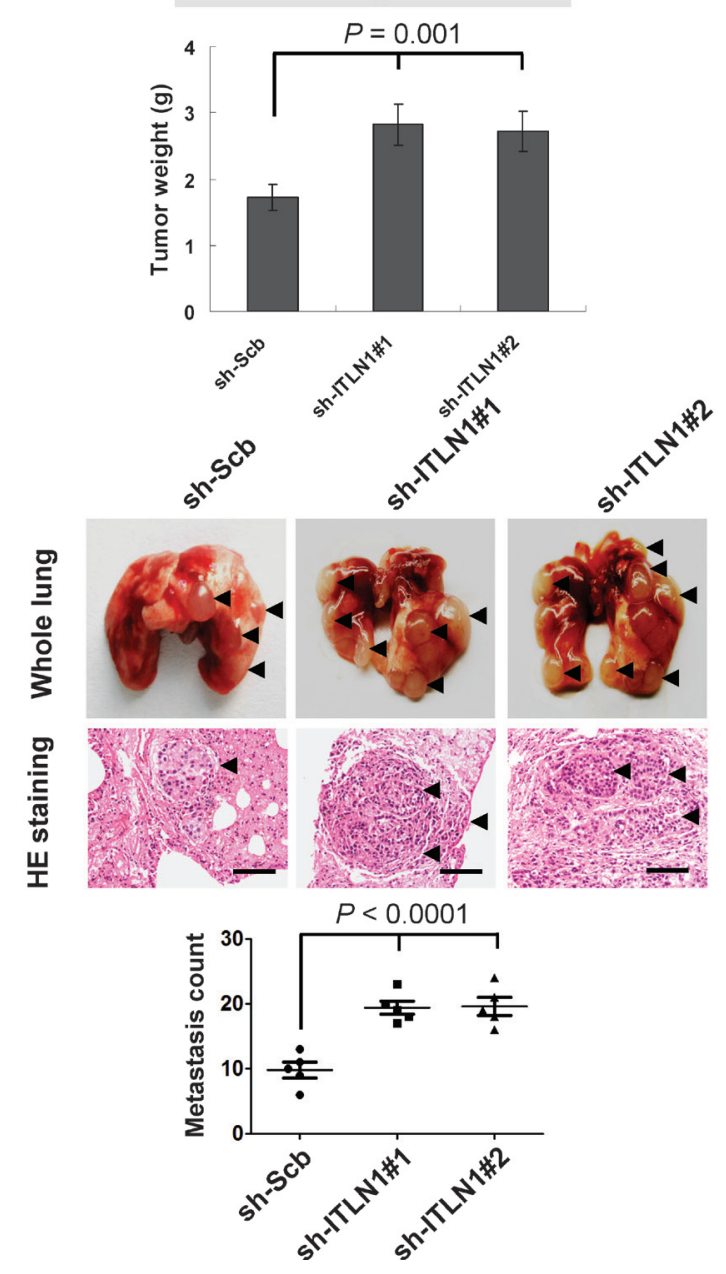

Figure 5: ITLN1 attenuated the growth and metastasis of gastric cancer cells in vivo. A and B. hypodermic injection of SGC-7901 cells into athymic nude mice established subcutaneous xenograft tumors. Four weeks later, mice $(n=5)$ from each group were sacrificed. Stable transfection of ITLN1 into cancer cells resulted in decreased tumor size ( $P<0.01$ vs. mock), and the mean tumor weight formed from ITLN1 over-expressing cells was significantly decreased. C. SGC-7901 cells were injected into the tail vein of athymic nude mice ( $n=5$ for each group). Cancer cells stably transfected with ITLN1 established significantly fewer metastatic colonies (arrowhead). Scale bars: $100 \mu \mathrm{m}$. D and E. stable transfection of sh-ITLN1 into cancer cells resulted in increased tumor size $(* P<0.01 \mathrm{vs.} \mathrm{sh-Scb), \text {and }}$ the mean tumor weight formed from ITLN1 knockdown cells was significantly increased. F. cancer cells stably transfected with sh-ITLN1 established significantly more metastatic colonies (arrowhead), when compared to those transfected with sh-Scb. Scale bars: $100 \mu \mathrm{m}$. 
consistent with the in vitro findings that ITLN1 suppressed the growth, migration, and invasion of gastric cancer cells.

\section{Expression of HNF4 $\alpha$ and ITLN1 was positively correlated and associated with improved survival in clinical gastric cancer cases}

To investigate the expression correlation between ITLN1 and HNF4 $\alpha$ in gastric cancer tissues, clinical specimens from 90 primary cases were collected. Western blot and real-time quantitative RT-PCR were applied to measure the expression levels of ITLN1 and HNF4 $\alpha$ in gastric cancer specimens, normal gastric mucosa, and cultured cell lines AGS, SGC-7901, MKN-28, and MKN-45. As shown in Figure 6A and Figure 6B, higher protein and transcript levels of ITLN1 or HNF4 $\alpha$ were observed in gastric cancer tissues and cell lines than those in normal gastric mucosa, while their expression levels gradually decreased along with the histological differentiation grades of gastric cancer (Figure 6C, $P<0.0001$ ), which was in line with the results from public databases (Figure S5A, Figure S5B, and Figure S5C). The ITLN1 levels were significantly lower in gastric cancer cases with poor differentiation $(P=0.019)$, deeper gastric wall invasion $(P<0.001)$, lymph node metastasis $(P<0.001)$, and advanced tumor-node-metastasis (TNM) stage $(P=0.001)$ (Table $\mathrm{S} 2)$. Notably, there was a positive correlation between ITLN1 and HNF4 $\alpha$ transcript levels in gastric cancer tissues (correlation coefficient $R=0.819$, $P<0.001$, Figure 6D), which was consistent with the results from public datasets (Figure S5D). Kaplan-Meier survival analysis revealed that patients with high ITLN1 $(P<0.001)$ or HNF4 $\alpha(P<0.001)$ expression had greater survival probability than those with low expression (Figure 6E). Taken together, these results demonstrated that the expression of HNF4 $\alpha$ and ITLN1 was positively correlated and associated with improved survival in clinical gastric cancer cases.

\section{DISCUSSION}

Since human ITLN1 was isolated from a small intestine cDNA library in 2001 [28], a series of studies have indicated the potential roles of ITLN1 in the tumorigenesis $[17,19,29,30]$. Ectopic expression of ITLN1 into prostate cancer cells results in significantly decreased in vitro cell viability; meanwhile, increased tumorigenicity and in vivo growth are observed in ITLN1 knockdown prostate cancer cells [29]. ITLN1 induces the apoptosis of hepatocellular carcinoma cells through inhibiting p53 deacetylation in a silent mating type information regulation 2 homolog 1-dependent manner [30]. Based on the high ITLN1 levels in colon adenocarcinoma, it is plausible to speculate the involvement of ITLN1 in gastrointestinal malignancies [17]. Our previous studies have shown the aberrant expression of ITLN1 in gastric cancer specimens, which was significantly associated with tumor progression and patients' outcome [19]. In the current study, we further demonstrated that secretory ITLN1 suppressed the growth, migration, invasion, and metastasis of gastric cancer cells in vitro and in vivo, suggesting the tumor suppressive roles of ITLN1 in gastric cancer.

$\mathrm{HNF} 4 \alpha$, a member of nuclear receptor superfamily, is a versatile transcription factor that regulates gene expression through binding to cognate DNA sequences [31]. Previous evidence shows that HNF4 $\alpha$ expression is diminished in hepatocellular carcinoma [20, 32-34], and loss of HNF4 $\alpha$ leads to increased hepatocyte proliferation and promotion of diethylnitrosamine-induced hepatic tumors secondary to aberrant c-Myc activation [26]. In addition, over-expression of HNF4 $\alpha$ induces the differentiation of hepatoma cells into more mature phenotypes, and abolishes the tumorigenesis [35]. Down-regulation of $\mathrm{HNF} 4 \alpha$ is also involved in the metastasis and worse prognosis of colorectal cancer [27]. Recent studies show that $\mathrm{HNF} 4 \alpha$ suppresses the $\beta$-catenin activity in hepatocytes, through increasing the E-cadherin $/ \beta$-catenin complex at the plasma membrane and subsequently decreasing the nuclear translocation of $\beta$-catenin, resulting in inhibition of epithelial to mesenchymal transition and carcinogenesis [20]. Moreover, HNF4 $\alpha$ is expressed in human gastric cancer [36], and absence of HNF4 $\alpha$ expression is related to tumor invasion [37]. However, the exact functions of HNF4 $\alpha$ in gastric cancer still remain largely unknown. In this study, we demonstrated that HNF4 $\alpha$ expression in gastric cancer specimens was associated with patients' survival. In addition, we found that HNF4 $\alpha$ inhibited the nuclear translocation and transcription activity of $\beta$-catenin, and suppressed the growth and aggressiveness of gastric cancer cells, suggesting the crucial roles of HNF4 $\alpha$ in the tumorigenesis and progression of gastric cancer.

Human $H N F 4 \alpha$ gene is regulated mainly at the transcriptional level [38]. The $H N F 4 \alpha$ promoter region contains several binding sites of transcription factors, such as hepatocyte nuclear factor 1 alpha, specificity protein 1 , hepatocyte nuclear factor 6 alpha, and GATA binding protein 6 , which are crucial for high HNF4 $\alpha$ expression in hepatocellular carcinoma and hepatoblastoma cells [38]. Transcription factor Snail represses the expression of $\mathrm{HNF} 4 \alpha$ in hepatocytes through direct binding with the $H N F 4 \alpha$ promoter region [39]. As a transcription repressor, high mobility group A2 suppresses the transcription of $H N F 4 \alpha$ in mammary epithelial cells via transforming growth factor beta 1-induced SMAD family member 3 signaling pathway [40]. In response to cellular stress, including chemotherapeutic drug (doxorubicin) treatment and ultraviolet irradiation, p53 protein is activated to suppress the HNF4 $\alpha$ expression via binding with its 
A

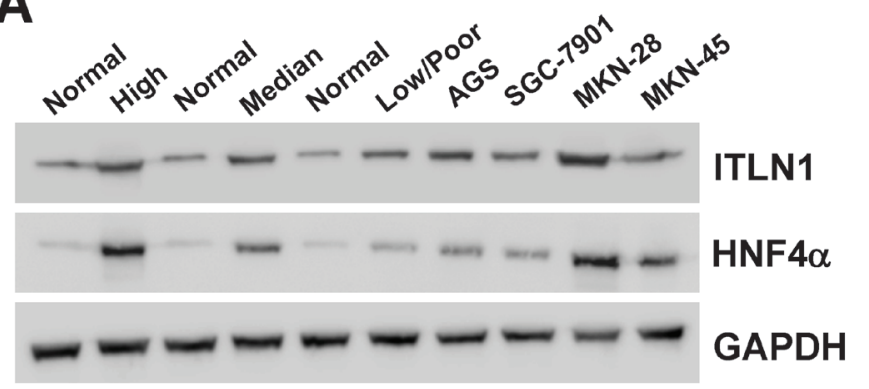

B

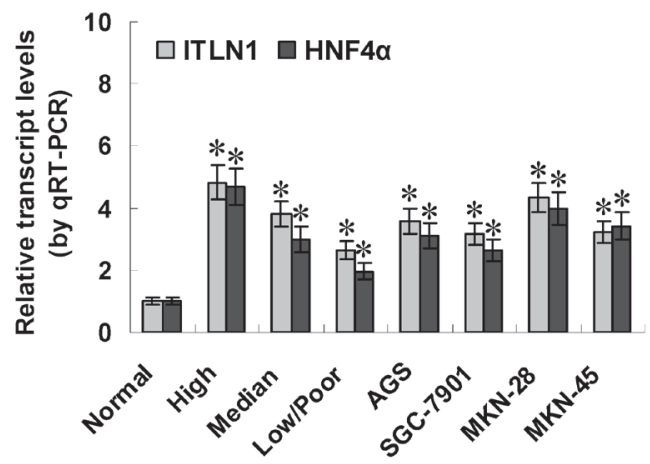

C

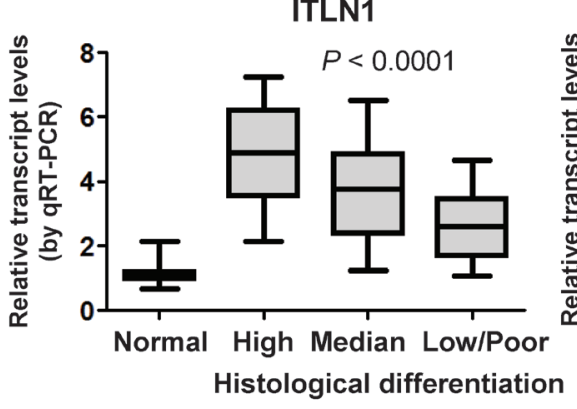

$\mathbf{E}$

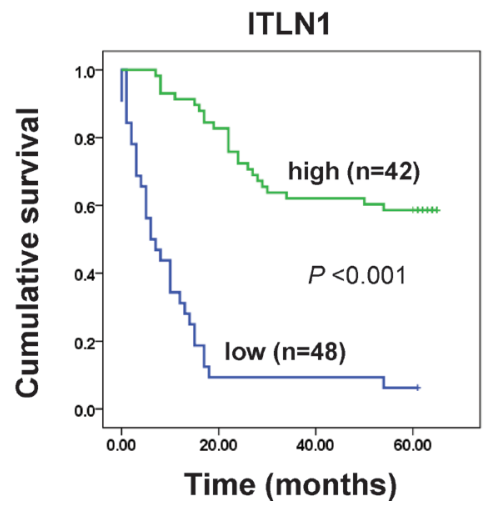

HNF4 $\alpha$
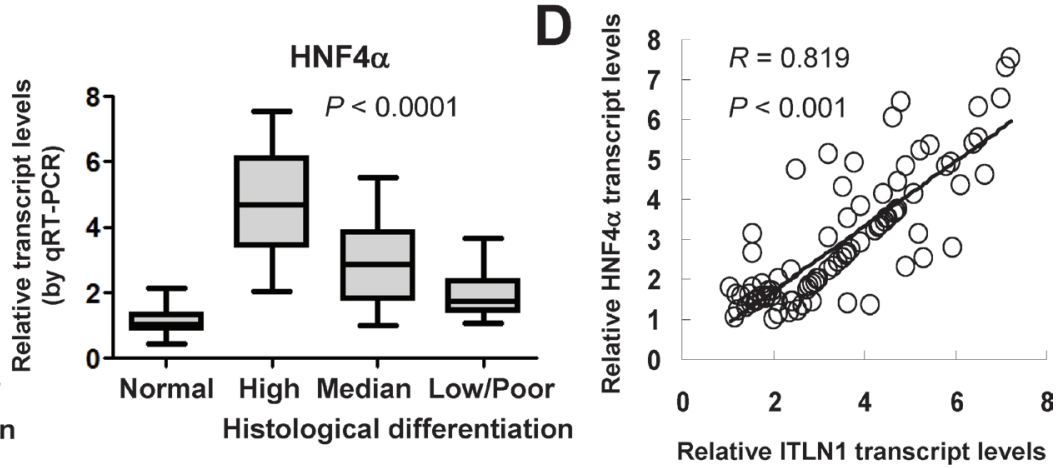

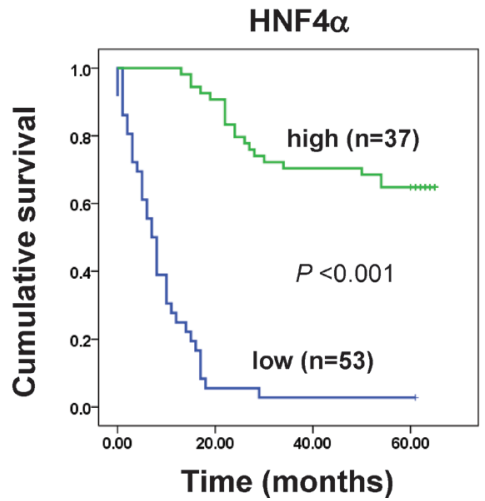

Figure 6: HNF4 $\alpha$ was positively correlated with ITLN1 expression in gastric cancer tissues and cell lines. A and B. western blot and real-time quantitative RT-PCR revealed higher expression levels of ITLN1 and HNF4 $\alpha$ in gastric cancer tissues $(n=90)$ and cultured cell lines AGS, SGC-7901, MKN-28, and MKN-45 than those in normal gastric mucosa $(n=30 ; * P<0.01$ vs. normal gastric mucosa). C. real-time quantitative RT-PCR indicated that the transcript levels of ITLN1 and $H N F 4 \alpha$ were gradually decreased in gastric cancer tissues with high $(n=22)$, median $(n=30)$, and low/poor $(n=38)$ differentiation. D. there was a positive correlation between ITLN1 and HNF4 $\alpha$ transcript levels in gastric cancer tissues $(n=90)$. E. Kaplan-Meier survival analysis revealed that patients with high expression of ITLN1 or HNF4 $\alpha$ had greater survival probability than those with low expression.

promoter in the hepatocytes [41]. In this study, our experimental evidence demonstrated that $H N F 4 \alpha$ was a target of transcription factor NFKB in gastric cancer cells. First, ChIP assay indicated the enrichment of NFKB on the $H N F 4 \alpha$ promoter. Second, the activity of $H N F 4 \alpha$ promoter was responsive to over-expression or knockdown of $\mathrm{NF \kappa B}$. Third, mutation of the NFKB binding site abolished its regulatory effects on the $H N F 4 \alpha$ promoter luciferase reporter. Finally, endogenous HNF4 $\alpha$ expression, both mRNA and protein, was altered by over-expression and knockdown of NFKB in gastric cancer cells, suggesting that $\mathrm{NF \kappa B}$ may regulate the $\mathrm{HNF} 4 \alpha$ expression by repressing its transcription.

It has been indicated that PI3K/AKT/IKK pathway is a major cascade mediating the activation of $\mathrm{NF \kappa B}$ in human cancer cells [25]. AKT/IKK signaling 
phosphorylates the I $\kappa \mathrm{B} \alpha$ at Ser32 and Ser36 to facilitate its ubiquitin-related degradation, resulting in release and nuclear translocation of $\mathrm{NF \kappa B}$ to regulate gene transcription [42]. In addition, PI3K/AKT may act through IKK $\alpha / \beta$ to increase the phosphorylation of

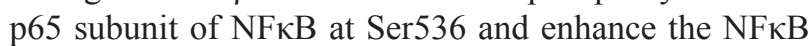
transactivation [42]. Our data showed that ITLN1 suppressed the activity of $\mathrm{NF} \kappa \mathrm{B}$ through inactivating $\mathrm{PI} 3 \mathrm{~K} / \mathrm{AKT} / \mathrm{IKK}$ pathway, resulting in increased $\mathrm{HNF} 4 \alpha$ expression in gastric cancer cells. Moreover, restoration of HNF $4 \alpha$ expression rescued the gastric cancer cells from ITLN1-mediated suppressive phenotypes, suggesting that ITLN1 may exert its tumor suppressive function, at least in part, through up-regulation of $\mathrm{HNF} 4 \alpha$ in gastric cancer.

In summary, for the first time, we have demonstrated that secretory ITLN1 efficiently inhibited the growth, invasion, and metastasis of gastric cancer cells in vitro and in vivo through up-regulating $\mathrm{HNF} 4 \alpha$ in a PI3K/ $\mathrm{AKT} / \mathrm{IKK} / \mathrm{NF} \kappa \mathrm{B}$ inactivation-dependent manner. Gastric cancer patients with high ITLN1 or HNF4 $\alpha$ expression had improved survival probability. This study extends our knowledge about the regulation of tumor suppressive genes associated with the progression of gastric cancer, and suggests that ITLN1 may be of potential values as a novel therapeutic target for gastric cancer.

\section{MATERIALS AND METHODS}

\section{Patient tissue samples}

Approval to conduct this study was obtained from the Institutional Review Board of Tongji Medical College (approval number: 2011-S085). Fresh specimens of 90 well-established primary gastric cancer cases were obtained from the Department of Surgery, Union Hospital of Tongji Medical College. Their pathological diagnosis was proved by at least two pathologists. The demographic and clinicopathological data of all patients were summarized in Table S2. Adjacent gastric mucosa specimens that contained no macroscopic tumor were also obtained, and the non-neoplastic areas were subsequently verified by microscopic histology to be free of tumor infiltration. The fresh tumor and adjacent normal gastric specimens were collected and stored at $-80^{\circ} \mathrm{C}$ until use.

\section{Cell culture}

Human gastric cancer cell lines AGS (CRL-1739), SGC-7901, MKN-28 and MKN-45 were obtained from the American Type Culture Collection (Rockville, MD) and Type Culture Collection of Chinese Academy of Sciences (Shanghai, China). Cell lines were authenticated on the basis of viability, recovery, growth, morphology, and isoenzymology by the provider. Cell lines were used within 6 months after resuscitation of frozen aliquots, and grown in RPMI1640 medium (Life Technologies, Inc.,
Gaithersburg, MD) supplemented with $10 \%$ fetal bovine serum (Life Technologies, Inc.), penicillin (100 U/ml), and streptomycin $(100 \mu \mathrm{g} / \mathrm{ml})$. Cells were maintained at $37^{\circ} \mathrm{C}$ in a humidified atmosphere of $5 \% \mathrm{CO}_{2}$. Cells were incubated in serum-free RPMI1640 for $4 \mathrm{hrs}$, and treated with recombinant ITLN1 protein (Enzo Life Sciences, Farmingdale, NY), LY294002, or BAY 11-7082 (Calbiochem, La Jolla, CA) as indicated.

\section{Gene over-expression and knockdown}

Human ITLN1 cDNA (942 bp) and $N F \kappa B-p 65$ cDNA (1656 bp) were amplified from the gastric cancer tissues (Table S3) and subcloned into pcDNA3.1 (Clontech, Mountain View, CA). The oligonucleotides encoding shRNA specific for ITLN1, $H N F 4 \alpha$, and $N F \kappa B-p 65$ (Table S3) were subcloned into the Bam $H$ I and Hind III restrictive sites of GV102 (Genechem Co., Ltd, Shanghai, China). The ITLN1 or ITLN1 shRNA vectors were transfected into cancer cells with Lipofectamine 2000 (Life Technologies, Inc.), and stable cell lines were screened by administration of neomycin (Invitrogen, Carlsbad, CA). The pcDNA3.1 and sh-Scb were applied as controls (Table S3).

\section{Rescue of target gene expression}

To restore the ITLN1 knockdown-induced downregulation of $\mathrm{HNF} 4 \alpha$, stable cell lines were transfected with the $H N F 4 \alpha$ expression vector provided by Dr. David Martinez Selva [43]. To rescue the ITLN1-induced up-regulation of HNF4 $\alpha$, the shRNA specific for $H N F 4 \alpha$ (Table S3) was transfected into cancer cells with Genesilencer Transfection Reagent (Genlantis, San Diego, CA). The sh-Scb was applied as a control (Table S3).

\section{Whole genome expression microarray and gene ontology analysis}

Whole genome expression was determined using high-throughput mRNA microarray analysis following Minimum Information About a Microarray Experiment (MIAME) guidelines. Briefly, total RNA of $1 \times 10^{6}$ cells was isolated using TRIzol ${ }^{\circledR}$ reagent (Life Technologies, Inc.). RNA was tested for purity and DNA contamination using A260/A280 ratio and standard denaturing agarose gel electrophoresis. Gene expression profiling was performed using Agilent Whole Human Genome Oligo Microarray $4 \times 44 \mathrm{~K}$ at Shanghai Technology Corporation (Shanghai, China). The slides were scanned with Agilent Microarray Scanner (Agilent Technologies, Santa Clara, CA). Raw data intensities were extracted from the aligned scanned images and normalized. Raw microarray data were submitted to the Gene Expression Omnibus database (Accession No. GSE58962). Gene ontology analysis was performed using Ingenuity Pathway Analysis (Qiagen, Redwood City, CA). 


\section{Western blot}

Tissue or cellular protein was extracted with $1 \times$ cell lysis buffer (Promega, Madison, WI). Culture supernatant was concentrated using a 10,000 MWCO spin column (Millipore, Billerica, MA). Protein expression in lysate or supernatant was analyzed by western blot as previously described [44-48], with antibodies specific for ITLN1, HNF4 $\alpha$ (Abcam, Cambridge, MA), $\beta$-catenin, phosphorylated AKT (p-AKT, T308), p-AKT (S473), AKT, phosphorylated IKK $\alpha / \beta$ (p-IKK $\alpha / \beta, \mathrm{S} 180 /$

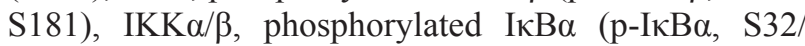

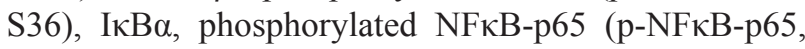
S536), NFkB-p65 (Cell Signaling, Danvers, MA), and glyceraldehyde 3-phosphate dehydrogenase (GAPDH; Santa Cruz Biotechnology, Santa Cruz, CA).

\section{Real-time quantitative RT-PCR}

Total RNA was isolated with RNeasy Mini Kit (Qiagen Inc., Valencia, CA). The reverse transcription reactions were conducted with Transcriptor First Strand cDNA Synthesis Kit (Roche, Indianapolis, IN). The PCR primers for ITLN1, HNF4 $\alpha, \beta$-catenin, AXIN2, CCND2, $R U N X 2, M M P 3$, and GAPDH were indicated in Table S4. Real-time PCR was performed with SYBR Green PCR Master Mix (Applied Biosystems, Foster City, CA). The fluorescent signals were collected during extension phase, and the $\mathrm{Ct}$ values of sample were calculated. The transcript levels were normalized to GAPDH and analyzed by $2^{-\Delta \Delta C t}$ method. The degree of transcript levels in cancer tissue specimens was classified into "high expression" and "low expression" groups, in which mRNA levels were higher or lower than the median expression in all samples, respectively.

\section{Luciferase reporter assay}

Human $H N F 4 \alpha$ promoter $(-606 /+128$ bp relative to TSS) was amplified from Genomic DNA by PCR (Table S3), and inserted into firefly luciferase reporter vector pGL3-Basic (Promega). The NFKB cis-reporter pNFкB-Luc was purchased from Stratagene (La Jolla, CA). The $\beta$-catenin activity reporter plasmids, TOPFLASH and FOP-FLASH, were obtained from Millipore. Dual-luciferase assay was performed as previously described [48, 49]. Relative $\beta$-catenin activation was determined by the TOP-FLASH/ FOP-FLASH ratio from at least three independent experiments.

\section{Chromatin immunoprecipitation}

ChIP assay was performed according to the manufacture's instructions of EZ-ChIP kit (Upstate Biotechnology, Temacula, CA) [48-50]. DNA was sonicated into fragments of an average size of $200 \mathrm{bp}$.
Different PCR primer sets were designed, distributing adjacent or distal to the NFKB binding site on the $H N F 4 \alpha$ promoter (Table S4). Real-time qPCR with SYBR Green PCR Master Mix was performed using ABI Prism 7700 Sequence Detector. The amount of immunoprecipitated DNA was calculated in reference to a standard curve and normalized to input DNA.

\section{Nuclear translocation assay}

Cancer cells were plated on coverslips, fixed with a solution of $95 \%$ ethanol and $5 \%$ glacial acetic acid at $-20^{\circ} \mathrm{C}$ for $20 \mathrm{~min}$, permeabilized with $0.3 \%$ Triton X-100 in phosphate buffered saline (PBS) at room temperature for $5 \mathrm{~min}$, and blocked with 5\% milk for $1 \mathrm{hr}$. Cells were incubated at $4{ }^{\circ} \mathrm{C}$ overnight with primary antibody specific for $\beta$-catenin (Millipore; 1:100 dilution). After washing with PBS, cells were incubated with Alexa Fluor 594 goat anti-rabbit $\operatorname{IgG}(1: 1000$ dilution) at room temperature for $30 \mathrm{~min}$. Cells were stained with 4', 6-diamidino-2phenylindole (DAPI, $300 \mathrm{nmol} / \mathrm{L}$ in PBS) to visualize nuclei and photographed with a Nikon Eclipse E800 microscope.

\section{Colony formation assay}

Cancer cells were seeded at a density of 300 cells $/ \mathrm{ml}$ on $35-\mathrm{mm}$ dishes. Colony formation assay was performed as previously described [45]. Positive colony formation (more than 50 cells/colony) was counted. The survival fraction of cells was expressed as the ratio of plating efficiency of treated cells to that of untreated control cells.

\section{Scratch migration assay}

Cancer cells were cultured in 24-well plates and scraped with the fine end of 1-ml pipette tips (time 0). Plates were washed twice with PBS to remove the detached cells, and incubated with the complete growth medium. Cell migration was photographed using 10 high-power fields, at $0,24 \mathrm{hr}$ post-induction of injury. Remodeling was measured as diminishing distance across the induced injury, normalized to the $0 \mathrm{hr}$ control, and expressed as outgrowth $(\mu \mathrm{m})[50]$.

\section{Matrigel invasion assay}

Matrigel invasion assay was performed using membranes coated with Matrigel matrix (BD Science, Sparks, MD). Homogeneous single cell suspensions $\left(1 \times 10^{5}\right.$ cells/well $)$ were added to the upper chambers and allowed to invade for $24 \mathrm{hrs}$ at $37^{\circ} \mathrm{C}$ in a $\mathrm{CO}_{2}$ incubator. Invaded cells were stained with $0.1 \%$ crystal violet for $10 \mathrm{~min}$ at room temperature and examined by light microscopy. Quantification of invaded cells was performed according to published criteria $[44,45]$. 


\section{In vivo growth and metastasis assay}

All animal experiments followed the national guidelines for the care and use of animals, and were approved by the Animal Care Committee of Tongji Medical College (approval number: Y20080290). For the in vivo tumor growth studies, 2-month-old male nude mice ( $n=5$ per group) were injected subcutaneously in the upper back with $1 \times 10^{6}$ cancer cells. One month later, mice were sacrificed and examined for tumor weight. The experimental metastasis $\left(0.4 \times 10^{6}\right.$ cancer cells per mouse, $n=5$ per group) studies were performed with 2 -month-old male nude mice as previously described [44, 45].

\section{Statistical analysis}

Unless otherwise stated, all data were shown as mean \pm standard error of the mean. The SPSS 18.0 statistical software (SPSS Inc., Chicago, IL) was applied for statistical analysis. The $\chi^{2}$ analysis and Fisher exact probability analysis were applied for comparison among the expression of ITLN1, HNF4 $\alpha$, and individual clinicopathological features. Pearson's coefficient correlation was applied for analyzing the relationship between ITLN1 and HNF4 $\alpha$ expression. The KaplanMeier method was used to estimate the survival rates, and the log-rank test was used to assess the survival difference. Difference of cancer cells was determined by $t$ test or analysis of variance (ANOVA).

\section{ACKNOWLEDGMENTS}

We are grateful for Dr. David Martinez Selva for providing the HNF4 $\alpha$ expression vector. This work was supported by the National Natural Science Foundation of China (No. 81101905, No. 81272779, No. 81372667, No. 81372401, No. 81472363, No. 81402301, No. 81402408), Fundamental Research Funds for the Central Universities (2012QN224, 2013ZHYX003, 01-18-530112, 01-18-530115), and Natural Science Foundation of Hubei Province (2014CFA012).

\section{CONFLICTS OF INTEREST}

The authors declare no conflict of interest.

\section{REFERENCES}

1. Terry MB, Gaudet MM, Gammon MD. The epidemiology of gastric cancer. Semin Radiat Oncol. 2002; 12:111-127.

2. Demetter P, Nagy N, Martin B, Mathieu A, Dumont P, Decaestecker C, Salmon I. The galectin family and digestive disease. J Pathol. 2008; 215:1-12.

3. Liu FT, Rabinovich GA. Galectins as modulators of tumour progression. Nat Rev Cancer. 2005; 5:29-41.
4. Paz A, Haklai R, Elad-Sfadia G, Ballan E, Kloog Y. Galectin-1 binds oncogenic H-Ras to mediate Ras membrane anchorage and cell transformation. Oncogene. 2001; 20:7486-7493.

5. van den Brule F. Galectin-1 accumulation in the ovary carcinoma peritumoral stroma is induced by ovary carcinoma cells and affects both cancer cell proliferation and adhesion to laminin-1 and fibronectin. Lab Invest. 2003; 83:377-386.

6. Ellerhorst J, Nguyen T, Cooper DN, Lotan D, Lotan R. Differential expression of endogenous galectin-1 and galectin-3 in human prostate cancer cell lines and effects of overexpressing galectin-1 on cell phenotype. Int J Oncol. 1999; 14:217-224.

7. John CM, Leffler H, Kahl-Knutsson B, Svensson I, Jarvis GA. Truncated galectin-3 inhibits tumor growth and metastasis in orthotopic nude mouse model of human breast cancer. Clin Cancer Res. 2003; 9:2374-2383.

8. Nagy N, Bronckart Y, Camby I, Legendre H, Lahm H, Kaltner H, Hadari Y, Van Ham P, Yeaton P, Pector JC, Zick Y, Salmon I, Danguy A, et al. Galectin-8 expression decreases in cancer compared with normal and dysplastic human colon tissue and acts significantly on human colon cancer cell migration as a suppressor. Gut. 2002; 50:392-401.

9. Tsuji S, Uehori J, Matsumoto M, Suzuki Y, Matsuhisa A, Toyoshima K, Seya T. Human intelectin is a novel soluble lectin that recognizes galactofuranose in carbohydrate chains of bacterial cell wall. J Biol Chem. 2001; 276:23456-23463.

10. Washimi K, Yokose T, Yamashita M, Kageyama T, Suzuki K, Yoshihara M, Miyagi Y, Hayashi H, Tsuji S. Specific expression of human intelectin-1 in malignant pleural mesothelioma and gastrointestinal goblet cells. PLoS One. 2012; $7:$ e39889.

11. Datta R, deSchoolmeester ML, Hedeler C, Paton NW, Brass AM, Else KJ. Identification of novel genes in intestinal tissue that are regulated after infection with an intestinal nematode parasite. Infect Immun. 2005; 73:4025-4033.

12. Pemberton AD, Knight PA, Gamble J, Colledge WH, Lee JK, Pierce M, Miller HRP. Innate BALB/c enteric epithelial responses to Trichinella spiralis: inducible expression of a novel goblet cell lectin, intelectin-2, and its natural deletion in C57BL/10 mice. J Immunol. 2004; 173:1894-1901.

13. Pemberton AD, Knight PA, Wright SH, Miller HRP. Proteomic analysis of mouse jejunal epithelium and its response to infection with the intestinal nematode, Trichinella spiralis. Proteomics. 2004; 4:1101-1108.

14. Yang RZ, Lee MJ, Hu H, Pray J, Wu HB, Hansen BC, Shuldiner AR, Fried SK, McLenithan JC, Gong DW. Identification of omentin as a novel depot-specific adipokine in human adipose tissue: possible role in 
modulating insulin action. Am J Physiol Endocrinol Metab. 2006; 290:E1253-E1261.

15. Carolan BJ, Harvey BG, De BP, Vanni H, Crystal RG. Decreased expression of intelectin 1 in the human airway epithelium of smokers compared to nonsmokers. J Immunol. 2008; 181:5760-5767.

16. Kuperman DA, Lewis CC, Woodruff PG, Rodriguez MW, Yang YH, Dolganov GM, Fahy JV, Erle DJ. Dissecting asthma using focused transgenic modeling and functional genomics. J Allergy Clin Immunol. 2005; 116:305-311.

17. Wali A, Morin PJ, Hough CD, Lonardo F, Seya T, Carbone M, Pass HI. Identification of intelectin overexpression in malignant pleural mesothelioma by serial analysis of gene expression (SAGE). Lung cancer. 2005; 48:19-29.

18. Tsuji S, Tsuura Y, Morohoshi T, Shinohara T, Oshita F, Yamada K, Kameda Y, Ohtsu T, Nakamura Y, Miyagi Y. Secretion of intelectin-1 from malignant pleural mesothelioma into pleural effusion. Br J Cancer. 2010; 103:517-523.

19. Zheng L, Weng M, Qi M, Qi T, Tong L, Hou X, Tong Q. Aberrant expression of intelectin-1 in gastric cancer: its relationship with clinicopathological features and prognosis. J Cancer Res Clin Oncol. 2012; 138:163-172.

20. Ning BF, Ding J, Yin C, Zhong W, Wu K, Zeng X, Yang W, Chen YX, Zhang JP, Zhang X, Wang HY, Xie WF. Hepatocyte nuclear factor 4 alpha suppresses the development of hepatocellular carcinoma. Cancer Res. 2010; 70:7640-7651.

21. Jho EH, Zhang $\mathrm{T}$, Domon $\mathrm{C}$, Joo CK, Freund $\mathrm{NN}$, Costantini F. Wnt/beta-catenin/Tcf signaling induces the transcription of Axin2, a negative regulator of the signaling pathway. Mol Cell Biol. 2002; 22:1172-1183.

22. Huang W, Chang HY, Fei T, Wu H, Chen YG. GSK3 beta mediates suppression of cyclin D2 expression by tumor suppressor PTEN. Oncogene. 2006; 26:2471-2482.

23. Gaur $\mathrm{T}$, Lengner CJ, Hovhannisyan $\mathrm{H}$, Bhat RA, Bodine PVN, Komm BS, Javed A, van Wijnen AJ, Stein JL, Stein GS, Lian JB. Canonical WNT signaling promotes osteogenesis by directly stimulating Runx 2 gene expression. J Biol Chem. 2005; 280:33132-33140.

24. Kwon M, Lee SJ, Wang Y, Rybak Y, Luna A, Reddy S, Adem A, Beaty BT, Condeelis JS, Libutti SK. Filamin A interacting protein 1-like inhibits WNT signaling and MMP expression to suppress cancer cell invasion and metastasis. Int J Cancer. 2014; 135:48-60.

25. Agarwal A, Das K, Lerner N, Sathe S, Cicek M, Casey G, Sizemore N. The AKT/Ikappa B kinase pathway promotes angiogenic/metastatic gene expression in colorectal cancer by activating nuclear factor-kappa B and beta-catenin. Oncogene. 2004; 24:1021-1031.

26. Walesky C, Edwards G, Borude P, Gunewardena S, O’Neil M, Yoo B, Apte U. Hepatocyte nuclear factor 4 alpha deletion promotes diethylnitrosamine-induced hepatocellular carcinoma in rodents. Hepatology. 2013; 57:2480-2490.

27. Oshima T, Kawasaki T, Ohashi R, Hasegawa G, Jiang S, Umezu H, Aoyagi Y, Iwanari H, Tanaka T, Hamakubo T, Kodama T, Naito M. Downregulated P1 promoterdriven hepatocyte nuclear factor- $4 \alpha$ expression in human colorectal carcinoma is a new prognostic factor against liver metastasis. Pathol Int. 2007; 57:82-90.

28. Lee JK, Schnee J, Pang M, Wolfert M, Baum LG, Moremen KW, Pierce M. Human homologs of the Xenopus oocyte cortical granule lectin XL35. Glycobiology. 2001; 11:65-73.

29. Mogal AP, van der Meer R, Crooke PS, Abdulkadir SA. Haploinsufficient prostate tumor suppression by Nkx3.1: a role for chromatin accessibility in dosage-sensitive gene regulation. J Biol Chem. 2007; 282:25790-25800.

30. Zhang YY, Zhou LM. Omentin-1, a new adipokine, promotes apoptosis through regulating Sirt1-dependent p53 deacetylation in hepatocellular carcinoma cells. Eur J Pharmacol. 2013; 698:137-144.

31. Lazarevich NL SD, Fleishman DI, Kustova IF, Morozova OV, Chuchuev ES, Patyutko YI. Deregulation of hepatocyte nuclear factor 4 (HNF4) as a marker of epithelial tumors progression. Exp Oncol. 2010; 32:167-171.

32. Tanaka T, Jiang S, Hotta H, Takano K, Iwanari H, Sumi K, Daigo K, Ohashi R, Sugai M, Ikegame C, Umezu H, Hirayama Y, Midorikawa Y, et al. Dysregulated expression of $\mathrm{P} 1$ and $\mathrm{P} 2$ promoter-driven hepatocyte nuclear factor- $4 \alpha$ in the pathogenesis of human cancer. J Pathol. 2006; 208:662-672.

33. Lazarevich NL, Cheremnova OA, Varga EV, Ovchinnikov DA, Kudrjavtseva EI, Morozova OV, Fleishman DI, Engelhardt NV, Duncan SA. Progression of $\mathrm{HCC}$ in mice is associated with a downregulation in the expression of hepatocyte nuclear factors. Hepatology. 2004; 39:1038-1047.

34. Kalkuhl A, Kaestner K, Buchmann A, Schwarz M. Expression of hepatocyte-enriched nuclear transcription factors in mouse liver tumours. Carcinogenesis. 1996; 17:609-612.

35. Yin $C$, Lin $Y$, Zhang $X$, Chen $Y X$, Zeng $X$, Yue HY, Hou JL, Deng X, Zhang JP, Han ZG, Xie WF. Differentiation therapy of hepatocellular carcinoma in mice with recombinant adenovirus carrying hepatocyte nuclear factor-4 $\alpha$ gene. Hepatology. 2008; 48:1528-1539.

36. Takano K, Hasegawa G, Jiang S, Kurosaki I, Hatakeyama K, Iwanari H, Tanaka T, Hamakubo T, Kodama T, Naito M. Immunohistochemical staining for P1 and $\mathrm{P} 2$ promoter-driven hepatocyte nuclear factor- $4 \alpha$ may complement mucin phenotype of differentiated-type early gastric carcinoma. Pathol Int. 2009; 59:462-470.

37. Uozaki H, Barua RR, Minhua S, Ushiku T, Hino R, Shinozaki A, Sakatani T, Fukayama M. Transcriptional 
factor typing with SOX2, HNF4aP1, and CDX2 closely relates to tumor invasion and Epstein-Barr virus status in gastric cancer. Int J Clin Exp Pathol. 2011; 4:230-240.

38. Hatzis P, Talianidis I. Regulatory mechanisms controlling human hepatocyte nuclear factor 4alpha gene expression. Mol Cell Biol. 2001; 21:7320-7330.

39. Cicchini C, Filippini D, Coen S, Marchetti A, Cavallari C, Laudadio I, Spagnoli FM, Alonzi T, Tripodi M. Snail controls differentiation of hepatocytes by repressing HNF $4 \alpha$ expression. J Cell Physiol. 2006; 209:230-238.

40. Ishikawa F, Nose K, Shibanuma M. Downregulation of hepatocyte nuclear factor- $4 \alpha$ and its role in regulation of gene expression by TGF- $\beta$ in mammary epithelial cells. Exp Cell Res. 2008; 314:2131-2140.

41. Maeda Y, Hwang-verslues WW, Wei G, Fukazawa T, Durbin ML, Owen LB, Liu X, Sladek FM. Tumour suppressor $\mathrm{p} 53$ down-regulates the expression of the human hepatocyte nuclear factor $4 \alpha(\mathrm{HNF} 4 \alpha)$ gene. Biochem J. 2006; 400:303-313.

42. Viatour P, Merville MP, Bours V, Chariot A. Phosphorylation of NF- $\kappa \mathrm{B}$ and $\mathrm{I} \kappa \mathrm{B}$ proteins: implications in cancer and inflammation. Trends Biochem. 2005; 30:43-52.

43. Simó R, Barbosa-Desongles A, Lecube A, Hernandez C, Selva DM. Potential role of tumor necrosis factor- $\alpha$ in downregulating sex hormone-binding globulin. Diabetes. 2012; 61:372-382.

44. Zheng L, Pu J, Qi T, Qi M, Li D, Xiang X, Huang K, Tong Q. miRNA-145 targets v-ets erythroblastosis virus E26 oncogene homolog 1 to suppress the invasion, metastasis, and angiogenesis of gastric cancer cells. Mol Cancer Res. 2013; 11:182-193.

45. Zheng L, Qi T, Yang D, Qi M, Li D, Xiang X, Huang K, Tong Q. microRNA-9 suppresses the proliferation, invasion and metastasis of gastric cancer cells through targeting cyclin D1 and Ets1. PLoS One. 2013; 8:e55719.

46. Zhang H, Pu J, Qi T, Qi M, Yang C, Li S, Huang K, Zheng L, Tong Q. MicroRNA-145 inhibits the growth, invasion, metastasis and angiogenesis of neuroblastoma cells through targeting hypoxia-inducible factor 2 alpha. Oncogene. 2014; 33:387-397.

47. Zhang H, Qi M, Li S, Qi T, Mei H, Huang K, Zheng L, Tong Q. microRNA-9 targets matrix metalloproteinase 14 to inhibit invasion, metastasis, and angiogenesis of neuroblastoma cells. Mol Cancer Ther. 2012; 11:1454-1466.

48. Li D, Mei H, Qi M, Yang D, Zhao X, Xiang X, Pu J, Huang K, Zheng L, Tong Q. FOXD3 is a novel tumor suppressor that affects growth, invasion, metastasis and angiogenesis of neuroblastoma. Oncotarget. 2013; 4:2021-2044.

49. Jiang G, Zheng L, Pu J, Mei H, Zhao J, Huang K, Zeng F, Tong Q. Small RNAs targeting transcription start site induce heparanase silencing through interference with transcription initiation in human cancer cells. PLoS One. 2012; 7:e31379.

50. Zheng L, Li D, Xiang X, Tong L, Qi M, Pu J, Huang K, Tong Q. Methyl jasmonate abolishes the migration, invasion and angiogenesis of gastric cancer cells through down-regulation of matrix metalloproteinase 14. BMC Cancer. 2013; 13:74. 